\title{
LOSS OF CORTICAL GRANULES IN RABBIT EGGS EXPOSED TO SPERMATOZOA IN VITRO
}

\author{
LYNN R. FRASER, PRAMILA V. DANDEKAR AND \\ MILDRED K. GORDON \\ Department of Obstetrics and Gynecology, Yale University School of Medicine, \\ New Haven, Connecticut 06510, U.S.A.
}

(Received 15th October 1971, accepted 15th December 1971)

Cortical granules are found in the unfertilized eggs of many invertebrates and vertebrates, including mammals, but are essentially absent in fertilized eggs (Austin, 1968). The extruded contents of the granules are thought to play a rôle in the prevention of polyspermy (Austin, 1961). In the sea urchin, the cortical granule breakdown occurs after sperm penetration has begun and appears to be a propagated reaction over the egg surface (Austin, 1961). Szollosi (1967), studying cortical granules in the hamster and rat, found that the granule breakdown in these species is generally activated by the attachment of a spermatozoon to an egg. Pikó (1969) reported that the reaction is triggered when membrane fusion and breakdown of the postnuclear cap region of the spermatozoon has begun. Thus, the presence or absence of cortical granules might be used diagnostically to determine whether an egg has been fertilized. This criterion has been applied to intact (cumulus and corona cells present) and corona-devoid (all cells removed) eggs exposed to spermatozoa in an in-vitro system.

Unfertilized eggs were obtained from does which had superovulated after treatment with FSH/LH, and the follicular cells were removed from some of the ova, as described by Fraser, Dandekar \& Vaidya (1971). Capacitated spermatozoa were obtained by flusing with medium the uterine horns of does mated 15 to $18 \mathrm{hr}$ before they were killed. Intact and corona-devoid eggs were added to the sperm suspension and at various intervals $(15,30,45 \mathrm{~min} ; 1,2,3,4 \mathrm{hr})$ two to four eggs from each group were removed and fixed in $3 \%$ glutaraldehyde

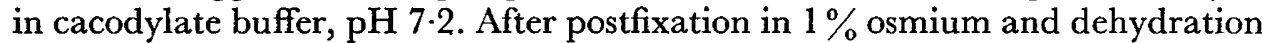
in alcohol, the eggs were flat embedded in Spurr (Polysciences). Sections were cut on a Reichert ultramicrotome, stained with uranyl acetate and lead citrate, and then examined in an Hitachi HU-12. Not all eggs were fixed. Four hours after mixing of eggs and spermatozoa, the remaining eggs were transferred to culture medium and incubated for another $21 \mathrm{hr}$. The dishes were then examined for cleaved embryos. All embryos were subsequently incubated in medium containing $10^{-5} \mathrm{~m}$-colchicine and chromosome complements were examined (see Fraser et al., 1971) in approximately eighty-five of the embryos.

Cortical granules were present in all the specimens fixed 15 and 30 min after insemination (Pl. 1, Fig. 1). Cortical granules, although present in the intact 
eggs $45 \mathrm{~min}$ after exposure to spermatozoa, were absent in one of the coronadevoid eggs (Pl. 1, Fig. 2). The earliest time at which cortical granules could not be found in intact eggs was $1 \mathrm{hr}$ after insemination. Subsequent timings $(2,3,4 \mathrm{hr})$ showed absence of cortical granules from most specimens. All of the corona-devoid eggs (55/55) and most of the intact eggs (49/51) which were retained for later examination had cleaved to the two- to four-cell stage $25 \mathrm{hr}$ after mixing of eggs and spermatozoa. All the embryos examined had diploid chromosome complements and were regarded as being derived from fertilized eggs. There has been no detectable parthenogenetic activation of eggs in this system (Fraser et al., 1971). Furthermore, parthenogenetically activated rabbit eggs retain their cortical granules (Flêchon, 1970).

Exact timing of sperm-egg union is difficult to determine. By recovering eggs from does at various intervals after normal mating, earlier workers (Pincus \& Enzmann, 1932; Austin \& Braden, 1954) determined that sperm penetration in rabbits generally occurs 10 to $13 \mathrm{hr}$ after coitus. The term sperm penetration often refers to penetration of egg investments and not to sperm attachment to the membrane of the vitellus itself. Such a method cannot give an exact determination of the time of fertilization since ovulation alone may occur over a rather broad time period. An in-vitro system has the distinct advantage that the time of exposure of the egg to spermatozoa is known. Brackett (1970), using the techniques of microcinematography and fertilization in vitro, was able to observe actual penetration of an egg by a spermatozoon. In this particular egg, attachment of the spermatozoon to the plasma membrane began at approximately $4 \mathrm{hr} 13 \mathrm{~min}$ after insemination.

Assuming that the cortical granule reaction is an indication of true attachment of a spermatozoon to an egg, the absence of cortical granules in a coronadevoid egg $45 \mathrm{~min}$ after insemination represents the earliest reported fertilization of a rabbit egg. The absence of cortical granules in an intact egg $1 \mathrm{hr}$ after insemination is the earliest report of fertilization of an egg surrounded by follicle cells, the state in which fertilization normally occurs. The rather large discrepancy between these observations and those of Brackett (1970) may simply reflect variation in the time of fertilization of different eggs. There is also the possibility that optimal conditions could not be maintained during the microcinematography so that sperm penetration and attachment were delayed.

It is not possible to know whether the earlier loss of granules in the coronadevoid egg is significant. Since the disappearance of cortical granules occurred at varing times in different eggs, the difference between the 45-min and 1-hr timings may simply reflect the general asynchrony in a small sample. In a larger sample, some intact eggs might also show signs of fertilization after 45 min exposure to spermatozoa. However, the corona-devoid egg would present a much shorter path to the vitellus surface than an intact egg, so that it is not unreasonable to suppose that sperm attachment might occur sooner in the denuded eggs.

We thank Susan Rice for her assistance in preparing the eggs for microscopy. This work was supported by Ford Foundation Grant 67-560. 
PI.ATE 1

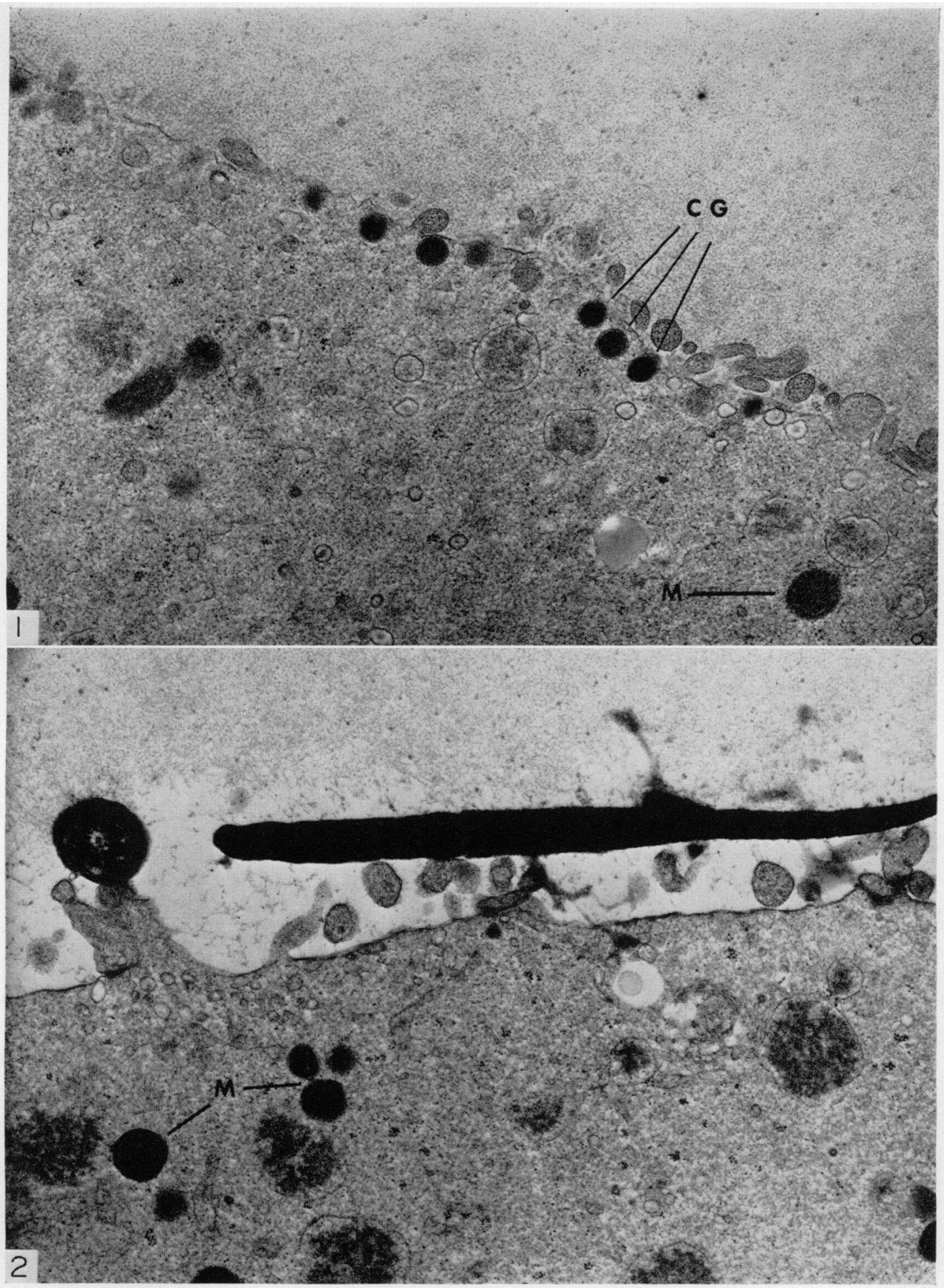

IIs. 1. Cortical region of an unfertilized rabbit egg with cortical granules present. CG, cortical granules; M, mitochondria. $\times 17,000$.

lisg. 2. Cortical region of fertilized rabbit egg with cortical granules absent. A supernumerary spermatozoon can be seen in the perivitelline space. $\times 14,000$. CG, cortical granules; M, mitochondria.

(Facing p. 296) 


\section{REFERENCES}

Austiv, G. R. (1961) The mammalian egg. Blackwell Scientific Publications, Oxford.

Austin, G. R. (1968) Ultrastructure of fertilization. Holt, Rinehart \& Winston, New York.

Austin, C. R. \& Braden, W. (1954) Time relations and their significance in the ovulation and penetration of eggs in rats and rabbits. Aust. 7. biol. Sci. 7, 179.

BRACKETT, B. (1970) In vitro fertilization of rabbit ova: time sequence of events. Fert. Steril. 21, 169.

FLÊCHON, J. (1970) Nature glycoprotéqque des granules corticaux de l'oeuf de lapine. Fnl Microscopie, 9, 221

Fraser, L., Dandekar, P. \& Vaidya, R. (1971) In vitro fertilization of tubal rabbit ova partially or totally denuded of follicular cells. Biol. Reprod. 4, 229.

Prkó, L. (1969) Gamete structure and sperm entry in mammals. In: Fertilization, Vol. 2, p. 325. Eds. C. Metz and A. Monroy. Academic Press, New York.

Pincus, G. \& Enzmann, E. (1932) Fertilisation in the rabbit. F. exp. Biol. 9, 403.

Szolzosi, D. (1967) Development of cortical granules and the cortical reaction in rat and hamster eggs. Anat. Rec. 159, 431. 